\title{
Effect of Intracranial Atherosclerotic Disease on Endovascular Treatment for Patients with Acute Vertebrobasilar Occlusion
}

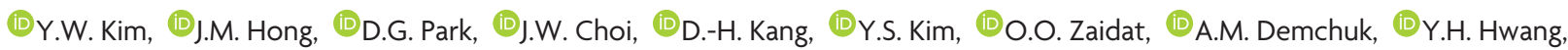 \\ and ${ }^{-1}$ J.S. Lee
}

\begin{abstract}
BACKGROUND AND PURPOSE: Although intracranial atherosclerotic disease is often encountered during endovascular treatment for acute vertebrobasilar occlusions, its clinical implication is not well-known. We aimed to evaluate whether intracranial atherosclerotic disease influences the clinical outcomes following endovascular treatment of acute vertebrobasilar occlusive stroke.
\end{abstract}

MATERIALS AND METHODS: Fifty-one patients with acute vertebrobasilar occlusive stroke were included. The onset-to-groin puncture time was $\leq 12$ hours, and aspiration- or stent-based thrombectomy was used as the primary treatment method. Following primary endovascular treatment, intracranial atherosclerotic disease (IAD group) was angiographically diagnosed when a fixed focal stenosis was observed at the occlusion site, whereas embolism (embolic group) was diagnosed if no stenosis was observed. Clinical and treatment variables were compared in both groups, and IAD was evaluated as a prognostic factor for clinical outcomes.

RESULTS: The baseline NIHSS score tended to be lower (14 versus 22, $P=.097)$ in the IAD group $(n=19)$ than in the embolic group $(n=$ 32). The procedural time was longer in the IAD group ( 96 versus 61 minutes, $P=.002$ ), despite similar rates of $\mathrm{TICl} 2 \mathrm{~b}-3(89.5 \%$ versus $87.5 \%$, $P=1.000$ ). The NIHSS score at 7 days was higher (21 versus $8, P=.060$ ) and poor outcomes (mRS $4-6$ at 3 months) were more frequent in the IAD group (73.7\% versus $43.8 \%, P=.038)$. IAD (odds ratio, $5.469 ; 95 \% \mathrm{Cl}, 1.09-27.58 ; P=.040$ ) was independently associated with poor outcomes.

CONCLUSIONS: An arterial occlusion related to IAD was associated with a longer procedural time and poorer clinical outcome. Further studies are warranted to elucidate the appropriate endovascular strategy.

ABBREVIATIONS: FAST $=$ forced arterial suction thrombectomy; IAD $=$ intracranial atherosclerotic disease

A cute vertebrobasilar occlusive stroke is a condition with high morbidity and mortality. ${ }^{1}$ With the advancement of endovascular treatment, the prognosis of acute ischemic stroke due to

Received November 7, 2015; accepted after revision April 24, 2016.

From the Departments of Neurology (Y.W.K., Y.H.H.), Radiology (Y.W.K., D.-H.K., Y.S.K.), and Neurosurgery (D.-H.K.), Kyungpook National University School of Medicine and Hospital, Daegu, Republic of Korea; Departments of Neurology (J.M.H., D.G.P., J.S.L.) and Radiology (J.W.C.), Ajou University School of Medicine and Hospital, Suwon, Republic of Korea; Department of Neurology (O.O.Z.), Froedtert Hospital and Medical College of Wisconsin, Milwaukee, Wisconsin; and Departments of Clinical Neurosciences and Radiology (A.M.D.), Hotchkiss Brain Institute, University of Calgary, Calgary, Alberta, Canada.

This research was partly supported by the Basic Science Research Program through the National Research Foundation of Korea funded by the Ministry of Education (NRF-2014R1A1A1008249, J.S.L.).

Please address correspondence to Jin Soo Lee, MD, PhD, Department of Neurology, Ajou University School of Medicine and Hospital, San 5, Woncheon-dong, Yeongtong-gu, Suwon, Kyungki-do, 443-721, Republic of Korea; e-mail: jinsoo22@ gmail.com; Yang-Ha Hwang, MD, PhD, Department of Neurology, Kyungpook National University School of Medicine and Hospital, 130, Dongduk-ro, Jung-gu, Daegu, 41944, Daegu, Republic of Korea, e-mail: yangha.hwang@gmail.com

- Indicates open access to non-subscribers at www.ajnr.org

http://dx.doi.org/10.3174/ajnr.A4844 intracranial large-artery occlusion has improved. ${ }^{2-8}$ Recently, successful clinical trials of endovascular treatment have been conducted, but these studies have mostly targeted anterior circulation occlusions. ${ }^{4-8}$ Evidence of endovascular treatment for posterior circulation occlusions is still lacking, though a few recent studies have shown better clinical outcomes compared with previous results. ${ }^{9,10}$

Underlying stenosis due to intracranial atherosclerotic disease (IAD) is often encountered during endovascular treatment for acute intracranial large-artery occlusion. Regarding the pathomechanism of stroke, in situ thrombotic occlusions may occur in addition to hemodynamic compromise due to stenosis. ${ }^{11-13}$ This IAD-related occlusion causes acute ischemic stroke and was reported to be more frequent in the posterior circulation than in the anterior circulation. ${ }^{14}$ According to previous literature, the prognosis of acute vertebrobasilar occlusions has been associated with various factors, including the initial severity of neurologic deficits, time to treatment, location of the occlusion, degree of collaterals, treatment modalities, and timely reperfusion. ${ }^{1,10,11,15-18}$ Nevertheless, to our knowledge, IAD 


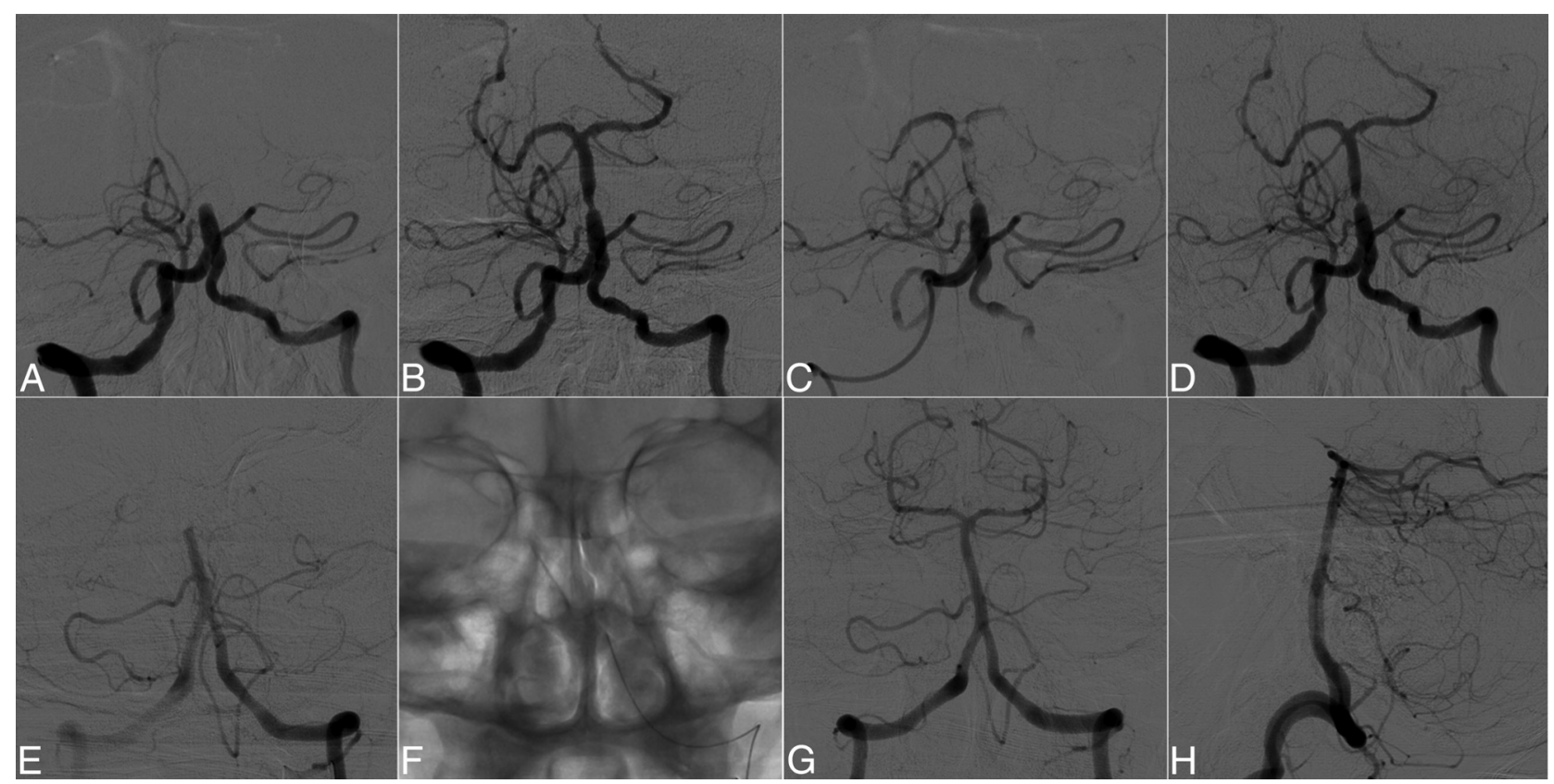

FIG 1. Sequential angiographic images of a patient with an atherosclerotic basilar occlusion $(A-D)$ and a patient with an embolic basilar occlusion $(E-H)$. An occlusion in the basilar artery in a 70-year-old woman $(A)$. Note significant focal stenosis at the occlusion site after the first pass of thrombectomy $(B)$. Follow-up angiography after 10 minutes demonstrates that the vessel is occluding again $(C)$. Significant fixed focal stenosis in the final angiogram after repeat thrombectomy $(D)$. An occlusion in the basilar artery of a 63-year-old man $(E)$. A single forced arterial suction thrombectomy $(F)$, and complete reperfusion of the basilar artery without residual stenosis as shown on the Towne and lateral views, respectively $(G$ and $H)$.

has not been evaluated as a prognostic factor, especially in posterior circulation occlusions.

In the present study, we evaluated whether IAD influences the clinical outcome following endovascular treatment of acute ischemic stroke caused by vertebrobasilar occlusion. We compared the interventional factors and clinical outcome between IAD-related and embolic occlusions.

\section{MATERIALS AND METHODS \\ Patients}

From consecutive patients with acute ischemic stroke admitted to 2 Korean university hospitals between March 2009 and March 2014, we retrospectively reviewed and enrolled those who met the following criteria: 1) patients who showed acute neurologic symptoms attributable to intracranial vertebral and/or basilar artery occlusion identified by CTA or MRA, 2) time from onset of symptoms to groin puncture of $\leq 12$ hours, and 3) endovascular treatment by using the forced arterial suction thrombectomy (FAST) method with a Penumbra reperfusion catheter (Penumbra, Alameda, California) or stent-based thrombectomy as the primary treatment. Patients were excluded if reperfusion was never observed, because both angiographic etiologies cannot be differentiated; or another etiology of stroke, including vasculitis, arterial dissection, or Moyamoya disease, was diagnosed by transfemoral cerebral angiography. The institutional review board of both hospitals approved this study, and informed consent was obtained from patients and/or their caregivers.

Using transfemoral cerebral angiography, we diagnosed IAD when a significant fixed focal stenosis was observed at the occlusion site during endovascular treatment or final angiography (Fig $1 A-D)$. Significant stenosis was defined according to the follow- ing criteria: 1) degree of fixed stenosis of $>70 \%,{ }^{19}$ or 2) moderate stenosis with either flow and perfusion impairment on angiography or an evident tendency toward reocclusion, ${ }^{13}$ even after sufficient primary endovascular treatment was performed. Underlying IAD can be observed from partial recanalization spontaneously or after intravenous thrombolytic treatment, but these cases were excluded in this study because primary thrombectomy devices for intracranial occlusions were allowed. An embolism was diagnosed if no stenosis was observed with sufficient blood flow and without a reocclusion tendency (Fig $1 E-H)$. The steps used to diagnose IAD in an occlusion during endovascular treatment are summarized in Fig 2. Patients were classified into the IAD or embolic group, and the clinical and treatment variables were compared.

\section{Acute Stroke Management Protocol and Endovascular Procedure}

The initial neurologic examination, which included the NIHSS, was performed in the emergency department. Nonenhanced brain CT was performed to evaluate brain parenchyma and to exclude intracerebral hemorrhage, while CTA or MRA was used to assess arterial occlusions. In terms of intravenous thrombolysis, recombinant tissue plasminogen activator was administered to patients within a 3-hour (until December 2012) or 4.5-hour window (from January 2013) according to the stroke guidelines. ${ }^{20}$ Additionally, endovascular treatment was used in the following cases: 1 ) a baseline NIHSS score of $\geq 4,2$ ) baseline modified Rankin Scale score of $\leq 2,3$ ) the presence of vertebrobasilar occlusion on CTA or MRA, 4) no intracerebral hemorrhage on brain $\mathrm{CT}$, and 5) groin puncture time of $\leq 12$ hours from the onset of symptoms.

AJNR Am J Neuroradiol 37:2072-78 Nov 2016 www.ajnr.org 
1 Confirm the intracranial large artery occlusion and exclude uncommon cerebral arterial diseases such as dissection, Moyamoya disease, and vasculitis by initial transfemoral cerebral angiography.

2 Exclude pure embolism when the occluded vessel is completely recanalized after primary thrombectomy.

Determine whether a remnant focal stenosis is significant following primary thrombectomy, or spontaneous or intravenous thrombolysis-induced partial recanalization.

3 - It is significant if the stenotic degree is over $70 \%$. [or]

- It is significant if the reocclusion tendency or flow impairment seen through the stenotic degree is moderate.

4 To angiographically exclude periprocedural complications such as vessel injury or vasospasm, repeat angiography is performed 10-20 minutes after final recanalization.

FIG 2. Steps to angiographically diagnosing intracranial atherosclerotic disease in an occlusion. angioplasty, ${ }^{23}$ stent placement, ${ }^{24}$ and intra-arterial tirofiban infusion, ${ }^{13}$ with consensus from the neurointerventionalist and neurologist. Follow-up angiography was performed 10-20 minutes after recanalization. If there were no changes or improvement of flow between the angiographic runs, the endovascular procedure was completed. However, if flow impairment or reocclusion occurred, we performed additional procedures, including repetitive mechanical thrombectomy or rescue treatments.

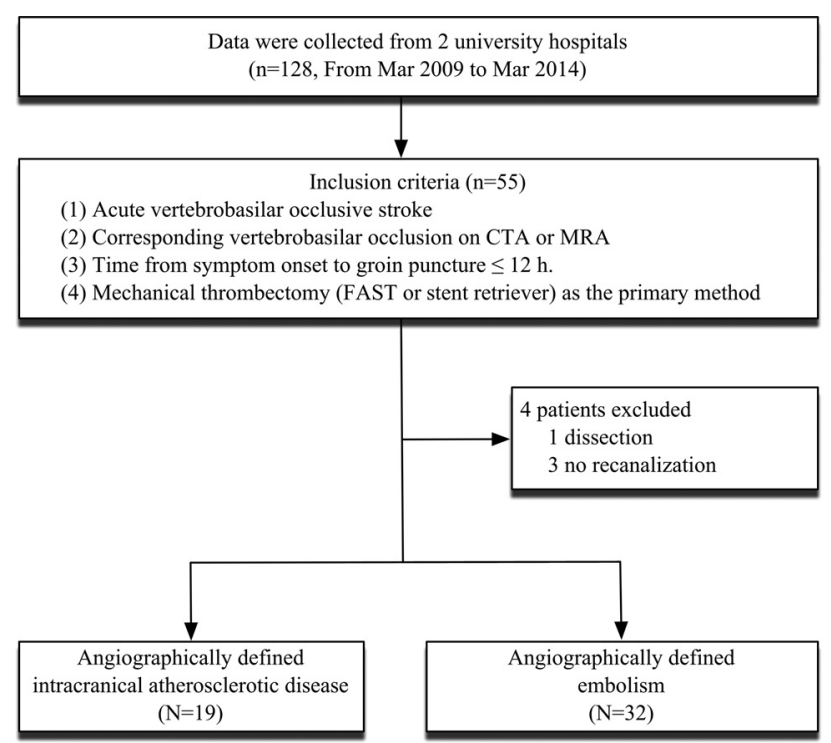

FIG 3. Flowchart of the present study.

First, a guide catheter was positioned from the femoral artery to the distal V2 segment of the dominant vertebral artery. In most cases, we used a conventional access device such as the Shuttle-SL guide sheath (Cook, Bloomington, Indiana) or Envoy (Codman \& Shurtleff, Raynham, Massachusetts), and not a balloon catheter, for posterior circulation treatment. Then, the neurointerventionalists decided to perform a mechanical thrombectomy by using a Penumbra reperfusion catheter (041/4MAX/3MAX; Penumbra) or a stent retriever (Solitaire AB/FR; Covidien, Irvine, California) as the primary strategy. For the FAST method, the Penumbra reperfusion catheter was placed at the proximal end of the clot. After wedging the clot into the catheter tip for several minutes, we withdrew the catheter gently while maintaining a negative pressure by using a $50-\mathrm{mL}$ syringe. ${ }^{21}$ In case of stent retrieval, a microcatheter was advanced through the occluded segment, and selective angiography was performed distal to the clot to confirm the landing zone of the stent retriever. The microcatheter was placed about $1 \mathrm{~cm}$ beyond the distal margin of the clot, and the stent retriever was deployed for several minutes. The stent retriever and microcatheter were drawn back into the guide catheter under remote aspiration through the guide catheter by suction by using a 50 -mL syringe.

These procedures were repeated until successful reperfusion. If reperfusion was not achieved or the occlusion was sustained, we applied rescue treatments, including the switching strategy, ${ }^{22}$

\section{Clinical and Radiographic Evaluation}

Data regarding the patient demographics, laboratory findings, imaging findings, and time intervals (ie, the symptom onset-todoor time, door-to-groin puncture, and groin puncture to reperfusion) were collected. The procedural time was defined from the groin puncture to reperfusion. The NIHSS scale was assessed at baseline, on day 7 , or at discharge if the patient was discharged earlier than day 7. The clinical outcome was assessed by using the $\mathrm{mRS}$ at 3 months, which was classified as favorable (mRS score, $0-3$ ) or poor (mRS score, 4-6). Neurologists and neuroradiologists from each hospital independently reviewed the radiologic data of their own hospital while blinded to the clinical information.

Locations of the occlusions were defined as follows: 1) the intracranial vertebral artery (limited to a single vertebral artery), from the V4 segment of the vertebral artery to below the vertebrobasilar junction; 2) the proximal basilar artery, from the vertebrobasilar junction to the anterior inferior cerebellar artery level; 3 ) the middle basilar artery, from the anterior inferior cerebellar artery to the superior cerebellar artery level; and 4) the distal basilar artery, from the superior cerebellar artery to the basilar artery top level. ${ }^{15}$ The presence of any posterior communicating artery was also recorded to assess the collateral flow.

The status of reperfusion was measured by using a TICI score. ${ }^{25}$ Successful reperfusion was defined as a TICI score of $2 b$ or 3. All patients underwent a follow-up nonenhanced brain CT scan 1 day after endovascular treatment. An intracerebral hemorrhage was classified according to the second European-Australasian Acute Stroke Study classification, ${ }^{26}$ and symptomatic intracerebral hemorrhage was defined as any hemorrhage associated with an NIHSS score increase of $\geq 4$ within 24 hours. $^{2}$

\section{Statistical Analysis}

Statistical analyses were performed by using SPSS for Windows (Version 20.0; IBM, Armonk, New York). The $\chi^{2}$ test or Fisher exact test was used for frequency comparisons, and the independent $t$ test and Mann-Whitney $U$ test were used for continuous and nonparametric variables, respectively. Binary logistic regression analysis was performed to confirm whether IAD was an independent predictor of poor outcome at 3 months. For this analysis, age, the baseline NIHSS score, the absence of intravenous rtPA, onset-to-reperfusion time, failed revascularization, and the 
Table 1: Baseline demographics and characteristics

\begin{tabular}{lccc}
\hline & IAD & Embolism & $P$ Value \\
\hline No. & 19 & 32 & \\
Age (yr) (mean) & $66.89 \pm 10.90$ & $67.84 \pm 10.79$ & .763 \\
Female sex (No.) (\%) & $6(31.6)$ & $11(34.4)$ & .838 \\
Hypertension & $17(89.5 \%)$ & $21(65.6 \%)$ & $.096^{\text {a }}$ \\
Diabetes & $8(42.1 \%)$ & $6(18.8 \%)$ & .071 \\
Hyperlipidemia & $11(57.9 \%)$ & $12(37.5 \%)$ & .157 \\
Atrial fibrillation & $2(10.5 \%)$ & $13(40.6 \%)$ & .023 \\
Baseline NIHSS (median) (IQR) & $14(6-23)$ & $22(14.5-26.5)$ & $.097^{\text {b }}$ \\
Intravenous rtPA & $4(21.1 \%)$ & $20(62.5 \%)$ & .004 \\
Calcification on brain CT & & & .018 \\
$\quad$ None & $3(16.7 \%)$ & $18(58.1 \%)$ & \\
$\quad$ Calcification in situ & $5(27.8 \%)$ & $4(12.9 \%)$ & \\
$\quad$ Calcification proximal to the occlusion & $10(55.6 \%)$ & $9(29.0 \%)$ & \\
Occlusion location on CTA & & & \\
$\quad$ Distal BA & $2(15.4 \%)$ & $21(87.5 \%)$ & \\
Middle BA & $5(38.5 \%)$ & $2(8.3 \%)$ & \\
Proximal BA & $4(30.8 \%)$ & $0(0 \%)$ & \\
Intracranial VA & $2(15.4 \%)$ & $0(0 \%)$ & \\
$\quad$ Other and mixed & $0(0 \%)$ & $1(4.2 \%)$ & \\
Presence of PcomA & $16(84.2 \%)$ & $27(84.4 \%)$ & 1.000 \\
\hline
\end{tabular}

Note:-IQR indicates interquartile range; BA, basilar artery; VA, vertebral artery; PcomA, posterior communicating artery.

${ }^{a}$ Fisher exact $t$ test.

${ }^{\mathrm{b}}$ Mann-Whitney $U$ test.

Table 2: Angiographic and clinical outcomes

\begin{tabular}{lccc}
\hline & IAD & Embolism & $\boldsymbol{P}$ Value \\
\hline Primary endovascular treatment methods & & & $.711^{\mathrm{a}}$ \\
$\quad$ FAST (No.) (\%) & $15(78.9 \%)$ & $27(84.4 \%)$ & \\
Stent retriever & $4(21.1 \%)$ & $5(15.6 \%)$ & \\
Frequency of rescue treatment & $13(68.4 \%)$ & $6(18.8 \%)$ & $<.001$ \\
$\quad$ Switching strategy & $3(16.7 \%)$ & $2(6.2 \%)$ & $.348^{\mathrm{a}}$ \\
Intra-arterial tirofiban & $6(31.6 \%)$ & $0(0 \%)$ & $.002^{\mathrm{a}}$ \\
Stenting & $6(31.6 \%)$ & $4(12.5 \%)^{\mathrm{b}}$ & $.146^{\mathrm{a}}$ \\
Angioplasty & $6(31.6 \%)$ & $4(12.5 \%)^{\mathrm{b}}$ & $.146^{\mathrm{a}}$ \\
Reocclusion during the procedure & $11(57.9 \%)$ & $5(15.6 \%)$ & .002 \\
Onset-to-groin puncture time (mean) (min) & $310.47 \pm 136.57$ & $263.13 \pm 146.28$ & .258 \\
Door-to-groin puncture time (mean) (min) & $131.78 \pm 46.94$ & $137.13 \pm 44.36$ & .694 \\
Procedure time (mean) (min) & $96.42 \pm 46.03$ & $61.16 \pm 31.84$ & .002 \\
Onset-to-recanalization time (mean) (min) & $415.74 \pm 128.51$ & $330.66 \pm 154.33$ & .049 \\
Successful recanalization & $17(89.5 \%)$ & $28(87.5 \%)$ & $1.000^{\mathrm{a}}$ \\
Intracerebral hemorrhage & $1(5.3 \%)$ & $3(9.4 \%)$ & .867 \\
$\quad$ Hemorrhagic infarction type 1 & $2(10.5 \%)$ & $3(9.4 \%)$ & \\
Hemorrhagic infarction type 2 & - & - & \\
Parenchymal hematoma type 1 & - & - & \\
Parenchymal hematoma type 2 & 0 & $3(9.4 \%)$ & $.285^{\mathrm{a}}$ \\
Subarachnoid hemorrhage & $21(9-26)$ & $8(5-21.5)$ & $.060^{\mathrm{c}}$ \\
NIHSS at 7 days (median) (IQR) & $2(10.5 \%)$ & $12(37.5 \%)$ & .037 \\
mRS 0-2 at 3 mo & $5(26.3 \%)$ & $18(56.2 \%)$ & .038 \\
mRS 0-3 at 3 mo & $4(21.1 \%)$ & $7(21.9 \%)$ & $1.000^{\mathrm{a}}$ \\
\hline Mortality at 3 mo & & & \\
\hline
\end{tabular}

Note:- IQR indicates interquartile range.

${ }^{a}$ Fisher exact $t$ test.

b The rescue treatment was not for the intracranial occlusion site but for extracranial proximal vertebral artery stenosis. Those cases were related to extracranial-to-intracranial tandem occlusions.

${ }^{c}$ Mann-Whitney $U$ test.

absence of a collateral posterior communicating artery were adjusted. A $P$ value $<.05$ was considered statistically significant.

\section{RESULTS}

Of 55 enrolled patients, 4 were excluded for the following reasons: Three had an undetermined etiology related to no angiographic reperfusion, and one had vertebral artery dissection (Fig 3). Finally, 51 patients were included. IAD accounted for $37.3 \%(n=$
$19)$ of patients, whereas an embolism accounted for $62.7 \%(n=32)$. The baseline demographics were similar between the 2 groups (Table 1). A trend toward lower baseline NIHSS scores was observed in the IAD group compared with the embolic group (median, 14 versus $22 ; P=.097)$. Among the stroke risk factors, atrial fibrillation was more prevalent in the embolic group (10.5\% versus $40.6 \%, P=.023)$. The location of the occlusion on CTA was different between the 2 groups. Occlusions in the middle basilar artery were more frequent in the IAD group (38.5\% versus $8.3 \%$ ), whereas occlusions in the distal basilar artery (15.4\% versus $87.5 \%$ ) were more frequent in the embolic group (overall, $P<.001)$. The incidence of intravenous rtPA administration was higher in the embolic group than in the IAD group ( $21.1 \%$ versus $62.5 \%, P=.004)$. The onset-to-groin puncture time did not differ between the IAD and embolic groups $(310 \pm 137$ minutes versus $263 \pm 146$ minutes, $P=.258$ ).

The rate of successful reperfusion did not differ between groups ( $89.5 \%$ versus $87.5 \%, P=1.000)$. The frequency of primary endovascular treatment methods also did not differ; the FAST method with a Penumbra reperfusion catheter was most commonly used ( $78.9 \%$ versus $84.4 \%, P=.711)$. The procedural time was significantly longer in the IAD group than in the embolic group (mean, $96.42 \pm 46.03$ minutes versus $61.16 \pm$ 31.84 minutes; $P=.002$ ). During the endovascular procedure, reocclusion after reperfusion of the target vessel occurred more frequently in the IAD group (57.9\% versus $15.6 \%, P=.002$ ), and this group required rescue treatment more frequently (68.4\% versus $18.8 \%, P<.001)$. Between the IAD and embolic groups, we used the following rescue treatments: conversion to another mechanical thrombectomy device $(16.7 \%$ versus $6.2 \%$, respectively; $P=.348$ ), angioplasty $(31.6 \%$ versus $12.5 \%$, respectively; $P=.146)$, stent placement $(31.6 \%$ versus $12.5 \%$, respectively; $P=.146$ ), and the administration of intra-arterial tirofiban $(31.6 \%$ versus $0 \%$, respectively; $P=.002)$. Four patients in the embolic group had extracranial-to-intracranial tandem occlusions, so angioplasty and stent placement were performed for extracranial proximal vertebral artery stenosis. Detailed information on the angiographic and clinical outcomes is presented in Table 2.

AJNR Am J Neuroradiol 37:2072-78 Nov 2016 www.ajnr.org 
The NIHSS score at 7 days tended to be higher (median, 21 versus $8 ; P=.060$ ), and a favorable outcome at 3 months was less frequent in the IAD group compared with the embolic group (26.3\% versus $56.2 \%, P=.038$; Fig 4 ). In the IAD group, $50 \%$ of patients had an mRS score of 5 compared with $13 \%$ in the embolic group; however, the mortality rate did not differ between groups (21.1\% versus $21.9 \%$, respectively; $P=1.000)$. Hemorrhagic complications also did not differ. By multiple logistic regression analysis, IAD (odds ratio, 5.469; 95\% confidence interval, 1.085$25.580 ; P=.040)$ was an independent predictor of a poor outcome (Table 3 ).

\section{DISCUSSION}

In the current study, we achieved an overall successful reperfusion rate of $83.3 \%$. In addition, $45.1 \%$ of the clinical outcomes were favorable, and the mortality rate was $21.6 \%$ after endovascular treatment of acute vertebrobasilar occlusions. These outcomes were comparable with those in previous studies. ${ }^{17,27}$ However, the outcomes were distinctive when occlusions were divided according to angiographically defined classifications (ie, IAD-related and embolic occlusions). In our analysis, IAD was an independent risk factor for poor outcomes.

IAD-related occlusions were frequent in our population. In the current study, IAD accounted for about $40 \%$ of the acute vertebrobasilar occlusions. This incidence is much higher than that in the Western population, in which intracranial stenosis was observed in only $5.5 \%$ of patients with stent-retriever thrombectomy. ${ }^{28}$ On the contrary, intracranial stenosis was observed in $22.9 \%$ of patients with multimodal endovascular treatment in a Korean study. ${ }^{29}$ IAD may be more frequent in the posterior cir-

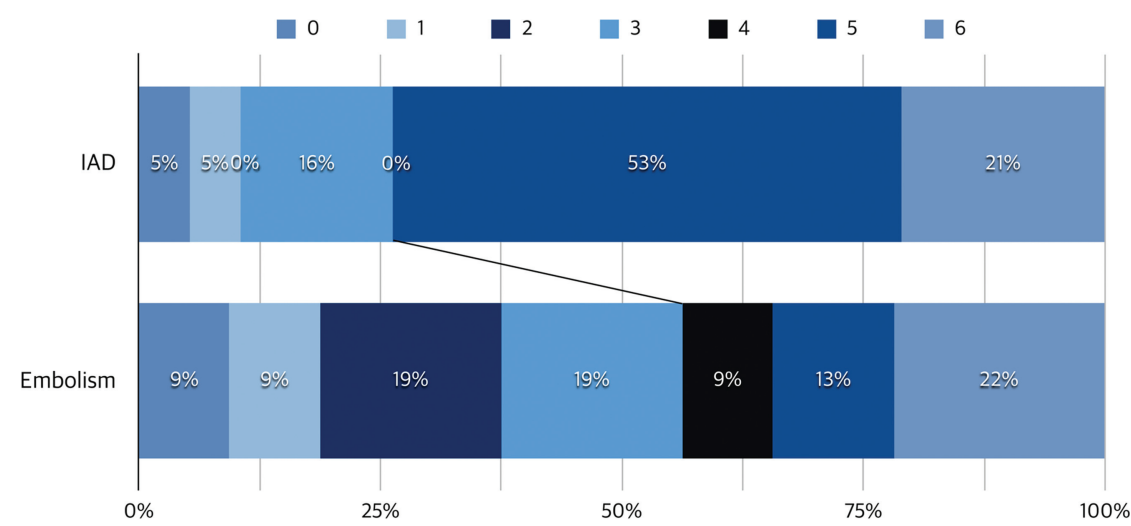

FIG 4. Modified Rankin Scale score at 3 months for each group. A favorable outcome is significantly less frequent in the intracranial atherosclerotic disease group compared with the embolism group, despite a similar mortality (mRS, $0-3: 26.3 \%$ versus $56.2 \% ; P=.038$ ). culation than in the anterior circulation. In another study from a Korean hospital, IAD accounted for $37 \%$ and $9 \%$ of posterior and anterior circulations, respectively. ${ }^{14}$ Along with a high incidence of IAD in the posterior circulation due to acute ischemic stroke, poor prognosis was a clinical implication in the current study.

Differentiating and defining IAD is of clinical importance because secondary or rescue endovascular treatment would be needed and the proper treatment method is essential. Our definition system was solely based on angiographic findings to determine the endovascular treatment strategy, and it was different from that of the Trial of ORG 10172 in Acute Stroke Treatment classification, which requires a full cardioembolism work-up and a secondary prevention plan. ${ }^{30}$ As mentioned already, hidden $\mathrm{IAD}$ is frequently observed in occlusions, and rescue treatment is often needed and should be urgently determined in the angiography suite.

To differentiate and define IAD, we used several steps based on an intracranial large-artery occlusion, as described in Fig 2. The first step was to exclude other uncommon etiologies such as dissection, Moyamoya disease, and vasculitis. ${ }^{14}$ Transfemoral cerebral angiography before endovascular treatment can show these uncommon etiologies because it is the criterion standard. The second step is to rule out pure embolism, which can be confirmed by primary thrombectomy endovascular treatment. If full recanalization without remnant stenosis is achieved at the occlusion site, the occlusion is thought to be due to a distant embolism. Because we do not need to consider additional therapy in the angiography suite, whether the embolic mechanism was unclear is irrelevant. If a focal fixed stenosis is sustained, interventionalists should consider whether IAD may be hidden in the occlusion.

The third step is to confirm whether the stenosis is significant. If severe stenosis is still observed after a repeat primary thrombectomy, IAD must be present. Usually, a stenotic degree of $>70 \%$ is considered a significant risk factor for the recurrence of ischemic stroke. ${ }^{19} \mathrm{~A}$ stenotic degree of $<70 \%$ but with a stenotic lesion that has been repeatedly occluded or a flow that is not fluent is also considered a significant stenosis. ${ }^{13}$ The fourth step is to wait 10-20 minutes after recanalization. We can assess reocclusion and differentiate the iatrogenic vessel injury or vasospasm. By following these steps, we can define the underlying

Table 3: Multiple logistic regression analyses for IAD as a poor prognostic factor at 3 months

\begin{tabular}{|c|c|c|c|c|}
\hline \multirow[b]{2}{*}{ Variables } & \multicolumn{2}{|c|}{ For Predicting mRS 4-6 } & \multicolumn{2}{|l|}{ For Predicting mRS 3-6 } \\
\hline & OR $(95 \% \mathrm{CI})$ & $P$ Value & OR $(95 \% \mathrm{Cl})$ & $P$ Value \\
\hline Age & 1.036 (0.972-1.105) & .275 & 1.023 (0.947-1.105) & .568 \\
\hline Baseline NIHSS & 1.060 (0.976-1.151) & .164 & 1.049 (0.956-1.151) & .316 \\
\hline Intravenous rtPA, not infused & $1.818(0.456-7.247)$ & .397 & $6.065(0.998-36.860)$ & .050 \\
\hline IAD & $5.469(1.085-27.580)$ & .040 & $8.738(0.960-79.570)$ & .054 \\
\hline Onset-to-reperfusion time & $0.999(0.994-1.003)$ & .593 & 0.995 (0.988-1.002) & .179 \\
\hline Failed revascularization $(\mathrm{TICl} 0-2 \mathrm{a}$ ) & $8.531(0.724-100.580)$ & .089 & $5.711(0.300-108.677)$ & .246 \\
\hline Absence of the collateral PcomA & $1.330(0.210-8.444)$ & .762 & $2.316 E+9(0.000$ to $-1.797 e+308)$ & .999 \\
\hline
\end{tabular}

Note:-PcomA indicates posterior communicating artery. 
IAD, which should exclude uncommon etiologies and procedural complications. During endovascular treatment, transfemoral cerebral angiography can be performed in real-time to determine whether there is an underlying IAD.

Various factors in IAD-related occlusions seemed to have affected the outcome. First, the location possibly affected it. Baseline CTA findings highlighted differences in the location of the occlusions. In accordance with prior studies, ${ }^{11,15,16}$ the most common location of occlusions was the proximal and middle basilar artery in the IAD group and the distal basilar artery in the embolic group. Additionally, the location of the occlusion is associated with the prognosis. ${ }^{11,31}$ For instance, an occlusion of the proximal and middle basilar artery, which serves most of the pons, can be related to extensive ischemia of the pons, leading to a fatal condition such as locked-in syndrome. ${ }^{32}$ In the Stenting vs Aggressive Medical Management for Preventing Recurrent Stroke in Intracranial Stenosis study, the basilar artery trunk was associated with poor outcomes because those procedures may disturb the blood flow of basilar perforators. ${ }^{33}$ In the IAD group of our study, $>50 \%$ of patients had an mRS score of 5 , and the locked-in syndrome can be associated with such disabilities.

Second, depending on the angiographic classification, the endovascular procedure differed. The IAD group required a longer procedural time than the embolic group, despite a similar final reperfusion rate. Frequent arterial reocclusions that required repetitive thrombectomy procedures and additional rescue treatments were attributed to the longer procedural duration. Theoretically, endovascular treatment by using mechanical thrombectomy with FAST and a stent retriever can remove a thrombus in the IAD lesion. ${ }^{34}$ In addition, the IAD lesion must have factors such as plaque disruption, endothelial damage or irritation, or a local platelet activation-prone situation, ${ }^{35}$ which causes frequent acute arterial reocclusion during endovascular treatment. ${ }^{13}$ In the current study, $68.4 \%$ of the IAD group required rescue treatment for reocclusion.

This study has several potential limitations. First, it was retrospective in nature, though the data were prospectively registered at each hospital. This study was intended for patients who were undergoing endovascular treatment; because the enrolled patients were not randomized and were limited to achieving recanalization, some selection bias may exist. Nonetheless, only 3 patients were excluded due to reperfusion failure, so its effect on the analyses was probably minor. Second, there may be confounding factors, including the choice of rescue treatment and management strategies after endovascular treatment, because the data were collected from 2 different university hospitals. Third, the radiologic definition system differentiating IAD-related and embolic occlusions should be further validated. Although we have focused on the usage of this system for hyperacute treatment and have done our best to gather expert opinions, there are still weaknesses. We do not know what happened in patients whose occluded arteries were never recanalized. In addition, about $10 \%$ of patients with atrial fibrillation were still present in the IAD group. Finally, this study did not provide a good strategy for endovascular treatment of IAD-related occlusions in the posterior circula- tion. Therefore, further studies are warranted to determine a better strategy.

\section{CONCLUSIONS}

In patients with acute vertebrobasilar stroke who underwent endovascular treatment, IAD-related arterial occlusion was associated with a complicated endovascular procedure and poor clinical outcomes despite successful reperfusion.

Disclosures: Osama O. Zaidat-UNRELATED: Consultancy: Stryker, Medtronic; Expert Testimony: payment to both me and my institution; Patents (planned, pending or issued): patent pending. Andrew M. Demchuk_UNRELATED: Grants/Grants Pending: Medtronic, ${ }^{*}$ Comments: unrestricted grant for the Endovascular Treatment for Small Core and Proximal Occlusion Ischemic Stroke trial; Consultancy: Medtronic, Comments: honorarium for Continuing Medical Education events. *Money paid to the institution.

\section{REFERENCES}

1. Smith WS. Intra-arterial thrombolytic therapy for acute basilar occlusion: pro. Stroke 2007;38:701-03 CrossRef Medline

2. Saver JL, Jahan R, Levy EI, et al; SWIFT Trialists. Solitaire flow restoration device versus the Merci retriever in patients with acute ischaemic stroke (SWIFT): a randomised, parallel-group, non-inferiority trial. Lancet 2012;380:1241-49 CrossRef Medline

3. Nogueira RG, Lutsep HL, Gupta R, et al; TREVO 2 Trialists. Trevo versus Merci retrievers for thrombectomy revascularisation of large vessel occlusions in acute ischaemic stroke (TREVO 2): a randomised trial. Lancet 2012;380:1231-40 CrossRef Medline

4. Berkhemer OA, Fransen PSS, Beumer D, et al. A randomized trial of intraarterial treatment for acute ischemic stroke. N Engl J Med 2015; 372:11-20 CrossRef Medline

5. Campbell BC, Mitchell PJ, Kleinig TJ, et al; EXTEND-IA Investigators. Endovascular therapy for ischemic stroke with perfusion-imaging selection. $N$ Engl J Med 2015;372:1009-18 CrossRef Medline

6. Goyal M, Demchuk AM, Menon BK, et al; ESCAPE Trial Investigators. Randomized assessment of rapid endovascular treatment of ischemic stroke. N Engl J Med 2015;372:1019-30 CrossRef Medline

7. Jovin TG, Chamorro A, Cobo E, et al; REVASCAT Trial Investigators. Thrombectomy within $\mathbf{8}$ hours after symptom onset in ischemic stroke. N Engl J Med 2015;372:2296-306 CrossRef Medline

8. Saver JL, Goyal M, Bonafé A, et al; SWIFT PRIME Investigators. Stent-retriever thrombectomy after intravenous t-PA vs. t-PA alone in stroke. N Engl J Med 2015;372:2285-95 CrossRef Medline

9. Eom YI, Hwang YH, Hong JM, et al. Forced arterial suction thrombectomy with the Penumbra reperfusion catheter in acute basilar artery occlusion: a retrospective comparison study in 2 Korean university hospitals. AJNR Am J Neuroradiol 2014;35:2354-59 CrossRef Medline

10. Singer OC, Berkefeld J, Nolte CH, et al; ENDOSTROKE Study Group. Mechanical recanalization in basilar artery occlusion: the ENDOSTROKE study. Ann Neurol 2015;77:415-24 CrossRef Medline

11. Eckert B, Kucinski T, Pfeiffer G, et al. Endovascular therapy of acute vertebrobasilar occlusion: early treatment onset as the most important factor. Cerebrovasc Dis 2002;14:42-50 CrossRef Medline

12. Schulte-Altedorneburg G, Hamann GF, Mull M, et al. Outcome of acute vertebrobasilar occlusions treated with intra-arterial fibrinolysis in 180 patients. AJNR Am J Neuroradiol 2006;27:2042-47 Medline

13. Kang DH, Kim YW, Hwang YH, et al. Instant reocclusion following mechanical thrombectomy of in situ thromboocclusion and the role of low-dose intra-arterial tirofiban. Cerebrovasc Dis 2014;37: 350-55 CrossRef Medline

14. Lee JS, Hong JM, Lee KS, et al. Endovascular therapy of cerebral arterial occlusions: intracranial atherosclerosis versus embolism. $J$ Stroke Cerebrovasc Dis 2015;24:2074-80 CrossRef Medline

15. Cross DT 3rd, Moran CJ, Akins PT, et al. Relationship between clot 
location and outcome after basilar artery thrombolysis. AJNR Am J Neuroradiol 1997;18:1221-28 Medline

16. Voetsch B, DeWitt LD, Pessin MS, et al. Basilar artery occlusive disease in the New England Medical Center Posterior Circulation Registry. Arch Neurol 2004;61:496-504 CrossRef Medline

17. Miteff F, Faulder KC, Goh AC, et al. Mechanical thrombectomy with a self-expanding retrievable intracranial stent (Solitaire $A B$ ): experience in 26 patients with acute cerebral artery occlusion. AJNR Am J Neuroradiol 2011;32:1078-81 CrossRef Medline

18. Pfefferkorn T, Holtmannspötter M, Schmidt C, et al. Drip, ship, and retrieve: cooperative recanalization therapy in acute basilar artery occlusion. Stroke 2010;41:722-26 CrossRef Medline

19. Kasner SE, Chimowitz MI, Lynn MJ, et al; Warfarin Aspirin Symptomatic Intracranial Disease Trial Investigators. Predictors of ischemic stroke in the territory of a symptomatic intracranial arterial stenosis. Circulation 2006;113:555-63 CrossRef Medline

20. Jauch EC, Saver JL, Adams HP, et al; American Heart Association Stroke Council, Council on Cardiovascular Nursing, Council on Peripheral Vascular Disease, Council on Clinical Cardiology. Guidelines for the early management of patients with acute ischemic stroke: a guideline for healthcare professionals from the American Heart Association/American Stroke Association. Stroke 2013;44: 870-947 CrossRef Medline

21. Kang DH, Hwang YH, Kim YS, et al. Direct thrombus retrieval using the reperfusion catheter of the Penumbra system: forced-suction thrombectomy in acute ischemic stroke. AJNR Am J Neuroradiol 2011;32:283-87 CrossRef Medline

22. Kang DH, Kim YW, Hwang YH, et al. Switching strategy for mechanical thrombectomy of acute large vessel occlusion in the anterior circulation. Stroke 2013;44:3577-79 CrossRef Medline

23. Kashiwagi J, Kiyosue H, Hori Y, et al. Endovascular recanalization of acute intracranial vertebrobasilar artery occlusion using local fibrinolysis and additional balloon angioplasty. Neuroradiology 2010;52: 361-70 CrossRef Medline

24. Eckert B, Koch C, Thomalla G, et al. Aggressive therapy with intravenous abciximab and intra-arterial rtPA and additional PTA/ stenting improves clinical outcome in acute vertebrobasilar occlusion: combined local fibrinolysis and intravenous abciximab in acute vertebrobasilar stroke treatment (FAST)—results of a multicenter study. Stroke 2005;36:1160-65 CrossRef Medline
25. Higashida RT, Furlan AJ, Roberts H, et al; Technology Assessment Committee of the Society of Interventional Radiology. Trial design and reporting standards for intra-arterial cerebral thrombolysis for acute ischemic stroke. Stroke 2003;34:e109-37 CrossRef Medline

26. Hacke W, Kaste M, Fieschi C, et al. Randomised double-blind placebo-controlled trial of thrombolytic therapy with intravenous alteplase in acute ischaemic stroke (ECASS II): Second EuropeanAustralasian Acute Stroke Study Investigators. Lancet 1998;352: 1245-51 CrossRef Medline

27. Lutsep HL, Rymer MM, Nesbit GM. Vertebrobasilar revascularization rates and outcomes in the MERCI and multi-MERCI trials. $J$ Stroke Cerebrovasc Dis 2008;17:55-57 CrossRef Medline

28. Gascou G, Lobotesis K, Machi P, et al. Stent retrievers in acute ischemic stroke: complications and failures during the perioperative period. AJNR Am J Neuroradiol 2014;35:734-40 CrossRef Medline

29. Yoon W, Kim SK, Park MS, et al. Endovascular treatment and the outcomes of atherosclerotic intracranial stenosis in patients with hyperacute stroke. Neurosurgery 2015;76:680-86; discussion 686 CrossRef Medline

30. Adams HP Jr, Bendixen BH, Kappelle LJ, et al. Classification of subtype of acute ischemic stroke: definitions for use in a multicenter clinical trial-TOAST. Trial of Org 10172 in Acute Stroke Treatment. Stroke 1993;24:35-41 CrossRef Medline

31. Brandt T, von Kummer R, Müller-Küppers M, et al. Thrombolytic therapy of acute basilar artery occlusion: variables affecting recanalization and outcome. Stroke 1996;27:875-81 CrossRef Medline

32. Nordgren RE, Markesbery WR, Fukuda K, et al. Seven cases of cerebromedullospinal disconnection: the "locked-in" syndrome. $\mathrm{Neu}$ rology 1971;21:1140-48 CrossRef Medline

33. Fiorella D, Derdeyn CP, Lynn MJ, et al; SAMMPRIS Trial Investigators. Detailed analysis of periprocedural strokes in patients undergoing intracranial stenting in Stenting and Aggressive Medical Management for Preventing Recurrent Stroke in Intracranial Stenosis (SAMMPRIS). Stroke 2012;43:2682-88 CrossRef Medline

34. Lee JS, Hong JM, Lee KS, et al. Primary stent retrieval for acute intracranial large artery occlusion due to atherosclerotic disease. $J$ Stroke 2016;18:96-101 CrossRef Medline

35. Bang OY. Intracranial atherosclerosis: current understanding and perspectives. J Stroke 2014;16:27-35 CrossRef Medline 